\title{
Analysis of Alphalactalbumin and Betalactoglobulin from the Rehydration of Bovine Colostrum Powder Using Cloud Point Extraction and Mass Spectrometry
}

\author{
Fan Zhang, Xiaohua Qi, Mingqiang Zou, and Jinfeng Li \\ Chinese Academy of Inspection and Quarantine, A3, North Gaobeidian Road, Chaoyang District, Beijing 100123, China \\ Correspondence should be addressed to Mingqiang Zou, mingqiangz@sina.com
}

Received 4 November 2011; Revised 26 December 2011; Accepted 3 January 2012

Academic Editor: Hui-Fen Wu

Copyright () 2012 Fan Zhang et al. This is an open access article distributed under the Creative Commons Attribution License, which permits unrestricted use, distribution, and reproduction in any medium, provided the original work is properly cited.

\begin{abstract}
Alphalactalbumin $(\alpha$-La) and betalactoglobulin $(\beta-\mathrm{Lg})$ in the rehydration of bovine colostrum powder were successfully separated by cloud point extraction using a nonionic surfactant Triton X-114. The effects of different factors, including the surfactant concentration, sample volume, electrolyte, and $\mathrm{pH}$ were discussed. The optimized conditions for cloud point extraction of alphalactalbumin $(\alpha$-La) and betalactoglobulin $(\beta-\mathrm{Lg})$ can be concluded that the best surfactant is $1 \%(\mathrm{w} / \mathrm{v})$ Triton X-114, 200 $\mu \mathrm{L}$ of sample volume, $150 \mathrm{mmol} / \mathrm{L} \mathrm{NaCl}$, and $6 \%(\mathrm{w} / \mathrm{v})$ sucrose. After cloud point extraction, the capillary electrophoresis is used to check the efficiency of the extraction procedure. The results had been effectively confirmed by the characterization with matrix-assisted laser desorption ionization time of flight mass spectrometry (MALDI-TOF MS).
\end{abstract}

\section{Introduction}

Bovine colostrum is an opaque white liquid which is a natural source of nutrition. Five main components in bovine colostrum are water, fats, proteins (e.g., caseins, albumins, and globulins), sugars (essentially lactose), and mineral salts. Since bovine colostrum spoils easily, it is sometimes processed into dairy products. The most durable form of bovine colostrum is bovine colostrum powder, which is produced by the dehydration of raw bovine colostrum. In developing countries, bovine colostrum powder is an important source of proteins in people's daily lives. Casein and whey proteins differ mainly in hydrophobicity and abundance. Casein is the major protein in cow's milk, and comprises about $80 \%$ of the total protein content of which the rest, $20 \%$, are the whey or serum protein $[1,2]$. Whey proteins display different structural characteristics and aminoacid compositions, with high nutritional level. Whey proteins contain alphalactalbumin $(\alpha$-La), betalactoglobulin $(\beta-\mathrm{Lg})$, immunoglobulin, lactoferrin, and bovine serum albumin [3]. Alphalactalbumin $(\alpha-\mathrm{La})$ and betalactoglobulin $(\beta-\mathrm{Lg})$ are two kinds of whey protein in bovine colostrum and specifically produced in the mammary epithelial cells only during lactation [4]. As a monomer, alphalactalbumin $(\alpha-\mathrm{La})$ and betalactoglobulin $(\beta-\mathrm{Lg})$ strongly bind calcium and zinc ions and may possess bactericidal or antitumor activity [5].

High-effect capillary electrophoresis (HPCE), namely, capillary electrophoresis (CE) is a rapid analytical technology. This technology already has applied to protein and aminofacid broadly for many years. Due to the appealing advantages in separation efficiency and resolution, small amounts of solvent and sample, CE have rapidly been applied for the assay in the protein separation field.

For a long time, the capabilities of matrix-assisted laser desorption/ionization (MALDI) mass spectrometry for the rapid evaluation of proteins have been proved. Furthermore, it has also been tested to be a valid tool in the dairy industry. Although the technique does not determine the exact concentrations of bovine colostrum proteins, the relative proportions of several main bovine colostrum proteins can be identified. In this experiment, a portion of bovine colostrum powder was rehydrated with water. Another portion was 
separated with CPE method and detectable differences in their MALDI spectra were found.

The present work describes alphalactalbumin $(\alpha$-La) and betalactoglobulin $(\beta-\mathrm{Lg})$ in the rehydration of bovine colostrum powder were successfully separated by cloud point extraction using a nonionic surfactant Triton X114. The separation was mainly based on their contrasting hydrophobicities, and our main goal was to achieve the highest concentration of alphalactalbumin $(\alpha$-La) and betalactoglobulin $(\beta-\mathrm{Lg})$ in the surfactant-poor phase obtaining high efficiency of CPE method. Since separation of these proteins using $\mathrm{CPE}$ depends on several variables, such as type and concentration of surfactant, $\mathrm{pH}$, net charge, size and sample volume $[6,7]$, the optimization design was concluded in [8]. The matrix-assisted laser desorption ionization-time of flight mass spectrometry (MALDI-TOF MS) was used to confirm the separation of alphalactalbumin $(\alpha-\mathrm{La})$ and betalactoglobulin $(\beta-\mathrm{Lg})$ from the rehydration of bovine colostrum powder.

\section{Materials and Methods}

2.1. Materials. Bovine colostrum powder (Sunlife bovine colostrum powder) was purchased in a local Chinese market. All the water used in the experiment was Milli-Q deionized water (Millipore, Billerica, MA, USA.). Acetonitrile (HPLC grade) was obtained from SK Chemicals (Ulsan, Korea). The $\alpha$-cyano-4-hydroxycinnamic acid (CHCA) was obtained from Applied Biosystems (Foster City, CA, USA). Trifluoroacetic acid (TFA) was obtained from SigmaAldrich (Steinheim, Germany). Tris (hydroxymethyl)aminomethane, hydrochloric acid- $\mathrm{HCl}$, sodium chloride$\mathrm{NaCl}$, isooctylphenyl ether (Triton X-114), and sucrose were obtained from Sigma-Aldrich (Steinheim, Germany).

2.2. Optimization Strategy. There were four factors of optimization studied in this experiment. The factors were Triton $\mathrm{X}-114$ concentration, sample volume, $\mathrm{NaCl}$ and sucrose concentration, and $\mathrm{pH}$. The surfactant solution was prepared with $10 \mathrm{mmol} / \mathrm{L}$ Tris- $\mathrm{HCl}(\mathrm{pH} 7.4), 150 \mathrm{mmol} / \mathrm{L} \mathrm{NaCl}$, and $6 \%(\mathrm{w} / \mathrm{v})$ sucrose [8]. $200 \mu \mathrm{L}$ bovine colostrum sample was added to the surfactant solution, and the solution was homogenized again. Finally, the samples were centrifuged at $1780 \times \mathrm{g}$ for $15 \mathrm{~min}$. The surfactant poor phase was analysed in the next step. The temperature was $25^{\circ} \mathrm{C}$ in all experiments.

2.3. Capillary Electrophoresis (CE). The CE was performed using a P/ACE MDQ capillary electrophoresis system (Beckman Coulter, Fullerton, CA, USA) under a normal polarity separation mode. A capillary (Beckman Coulter, Fullerton, CA, USA) with $50 \mathrm{~cm}$ effective length $(60 \mathrm{~cm}$ total $)$ and an inner diameter (I.D.) of $75 \mu \mathrm{m}$ was used with an applied voltage of $25 \mathrm{kV}$ at $20^{\circ} \mathrm{C}$. Prior to use the capillary for the first time, a rinse for $1 \mathrm{~min}(30 \mathrm{psi})$ with $0.1 \mathrm{~mol} / \mathrm{L}$ $\mathrm{HCl}$ was performed. A rinse for $10 \mathrm{~min}(30 \mathrm{psi})$ with the running buffer was performed then equilibrate the capillary for $10 \mathrm{~min}(25 \mathrm{kV})$. Finally a rinse for $10 \mathrm{~min}(30 \mathrm{psi})$ was performed The temperature of the separation capillary column was thermostated at $20^{\circ} \mathrm{C}$.

Among each runs, the capillary was rinsed with $0.1 \mathrm{~mol} / \mathrm{L}$ $\mathrm{HCl}$ for $0.5 \mathrm{~min}$ and then with the electrophoresis buffer for $1.5 \mathrm{~min}$. The separation buffer was $50 \mathrm{mM}$ Citrate buffer $(\mathrm{pH}$ 3.0 ), and the applied voltage is $25 \mathrm{kV}$. The electrophoresis buffers were filtered through $0.22 \mu \mathrm{m}$ filter before use. The samples were dissolved in $1 \mathrm{~mL}$ of buffer and filtered $[0.22 \mu \mathrm{m}$ (Millipore)] for CE analysis. Samples were injected into the capillary using pressure at $0.5 \mathrm{psi}$ for $10 \mathrm{~s}$. The absorbance was measured at a wavelength of $214 \mathrm{~nm}$ for the detection of protein.

2.4. MALDI-TOF Sample Preparation. To prepare a saturated solution of CHCA matrix: $10 \mathrm{mg}$ of the dry $\mathrm{CHCA}$ matrix was added to a tube containing $1 \mathrm{~mL}$ solution of water/acetonitrile/0.1\% TFA $(4 / 5 / 1, \mathrm{v} / \mathrm{v} / \mathrm{v})$. The tube was vortexed thoroughly for 1 minute and then centrifuged for 1 minute. $0.5 \mu \mathrm{L}$ of the sample/matrix $(1 / 5, \mathrm{v} / \mathrm{v})$ mixture was spotted per well on a stainless steel MALDI sample plate.

2.5. Mass Spectrometry. All the MALDI measurements were performed on a 4700 Proteomics Analyzer (Applied Biosystems, Foster City, CA, USA) equipped with a Nd:YAG laser $(355 \mathrm{~nm})$ operating at $200 \mathrm{~Hz}$. Ions formed by a pulsed laser beam were accelerated to 20 Kilo Volts in positive ion linear mode with a $740 \mathrm{~ns}$ delay times. The Bin Size was set to $10 \mathrm{~ns}$. The input bandwidth was set to $25 \mathrm{MHz}$. The acquisition method was set as follows: 60 subspectra were acquired on one spot and 25 shots were averaged per subspectrum, so one MALDI spectrum was the accumulated spectra of a total of 1500 shots per spot. For each sample, five spots were equally spotted and examined, and the acquisition method ran three times per spot. The final data were the trimmed means of the results of these 15 parallel tests as a whole. This instrument operating parameters were optimized for ion peaks corresponding to apomyoglbin (horse, $\mathrm{m} / \mathrm{z}$ 16952), Thioredoxin (E. coli, $\mathrm{m} / \mathrm{z} 11674$ ), and insulin (bovine, $\mathrm{m} / \mathrm{z}$ 5734).

\section{Results and Discussion}

3.1. CE Analysis Method and Results. To highlight the extraction of whey proteins from bovine colostrum and their separation from casein proteins by cloud point extraction, CE was used to identify $\alpha$-lactalbumin and $\beta$-lactoglobulin extracted from the rehydration of bovine colostrum powder. The electropherograms of standard and cloud point extraction sample from the rehydration of bovine colostrum powder were shown in Figures 1(a) and 1(b) and Figure 1(c), respectively. The retention time of $\alpha$-lactalbumin and $\beta$ lactoglobulin was about 10 and 15 min under the optimal separation condition. In Figure 1(c), there were only two whey protein peaks ( $\alpha$-lactalbumin and $\beta$-lactoglobulin). It was proved right with MALDI-TOF MS in the next experiment. From Figure 1(c), it is also proved the efficiency of the extraction procedure is successful. 


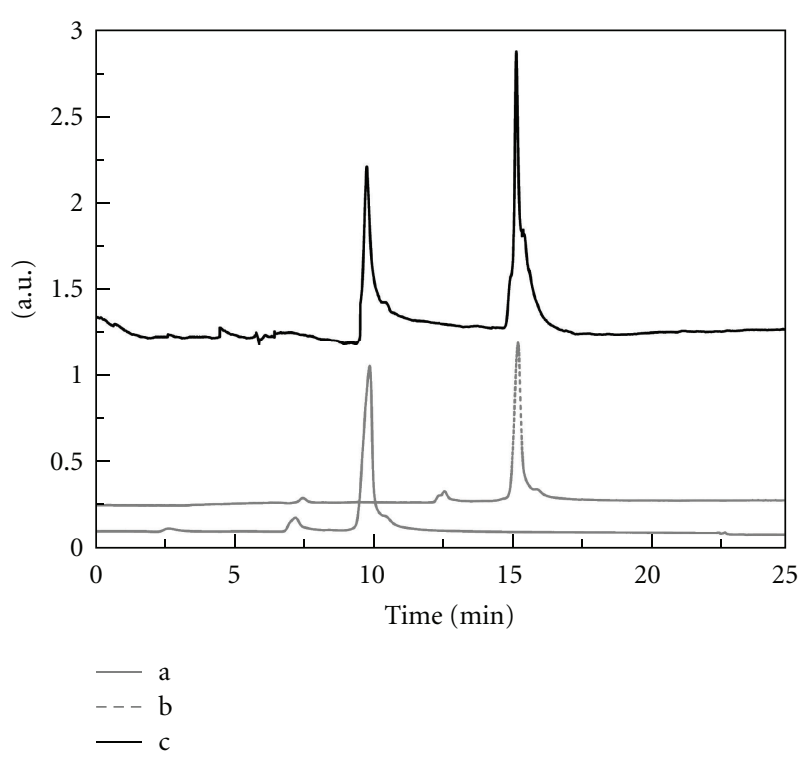

FIGURE 1: The electropherograms of standard substance and rehydration of bovine colostrum powder after cloud point extraction. There are alphalactalbumin (a), betalactoglobulin (b), and the sample (c).

3.2. MALDI-TOF MS Analysis. To highlight the extraction of whey proteins from bovine colostrum and their separation from casein proteins by CPE, MALDI-TOF MS to intact samples of the two protein fractions was applied. A simple sample treatment that only involved dilution of precipitated proteins was performed. Figure 2(a) displays the mass spectra obtained, and it summarizes different proteins identified in the surfactant poor and water phases. The theoretical molar masses are in agreement with those previously described for whole cow bovine colostrum protein analyses by MALDITOF MS.

The mass spectra of Figure 2(a) show ions of ca.m/z11958 and 23919 corresponding to the $\alpha$-casein and $\beta$-casein, respectively. Those ions in Figure 2(b) of higher $\mathrm{m} / \mathrm{z}$ values correspond to $\alpha$-lactalbumin $(\mathrm{m} / \mathrm{z} 14152)$ and $\beta$-lactoglobulin (m/z18318). Finally, the ion of ca.m/z 14152 in Figure 2(b) probably corresponds to species originating from lactose addition to $\alpha$-lactalbumin. The main proteins identified in the surfactant poor phase (Figure 2(b)) were $\alpha$-lactalbumin and $\beta$-lactoglobulin, which are fractions of the whey proteins [2]. Besides such proteins, $\alpha$-casein and $\beta$-casein were also detected in the water phase. In fact, both last proteins also present amphiphilic character $[4,5]$, corroborating their presence in the surfactant poor phase.

\section{Conclusion}

CPE was efficiently employed to cow bovine colostrum samples being able to extract and separate whey from casein proteins using only $200 \mu \mathrm{L}$ of sample volume, sample volume without any sample pretreatment. Triton X-114 (1\%,w/v), $150 \mathrm{mmol} / \mathrm{L} \mathrm{NaCl}$, and sucrose $(6 \%$, w/v) were used at

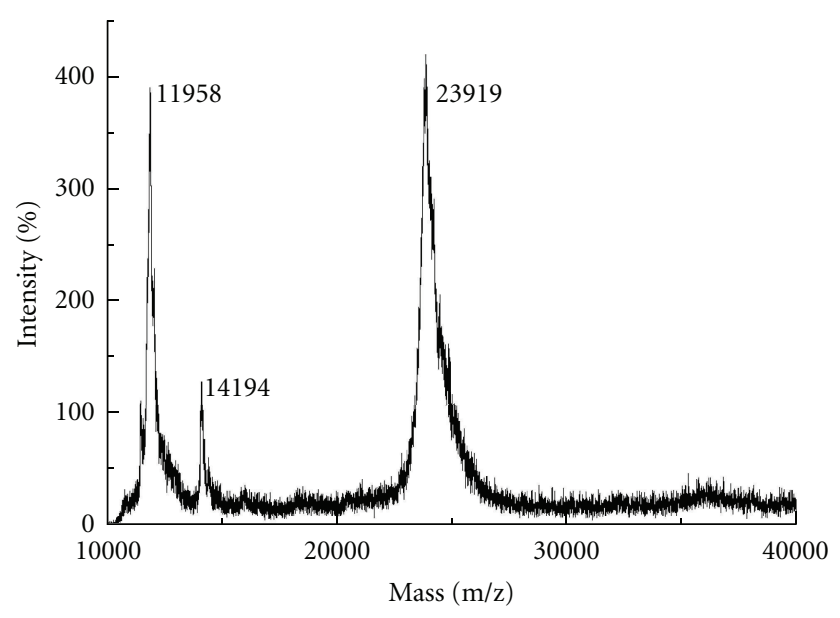

(a)

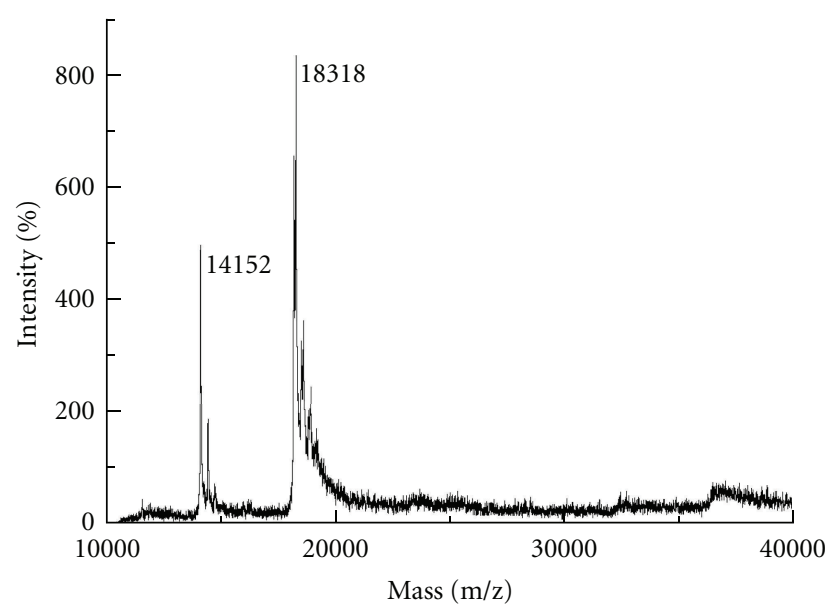

(b)

Figure 2: The MALDI-TOF mass spectra of bovine colostrum powder samples diluted with water rehydration (a) and bovine colostrum powder after cloud point extraction (b).

pH 7.0 for protein separations. At such conditions, good partition coefficient was obtained, allowing the separation of $\alpha$-lactalbumin and $\beta$-lactoglobulin (present in the surfactant poor phase) from casein proteins (present in the water phase) in only $15 \mathrm{~min}$ and with minimum costs, indicating that the proposed factorial design was successfully applied in the experimental domain employed and the main objective of this work attained. Although the partition coefficient was obtained, it is important to comment that some hydrophobic proteins were achieved in the surfactant poor phase and vice versa, as demonstrated through MALDI-TOF MS analysis. After cloud point extraction, the capillary electrophoresis was used to check the efficiency of the extraction procedure. The results had been effectively confirmed by the characterization with matrix-assisted laser desorption ionization time of flight mass spectrometry (MALDI-TOF MS). Finally, the adopted strategy could also be used for separating those low-abundant proteins in bovine colostrum after properly optimizing the CPE method for such task. 


\section{Acknowledgments}

This work was financially supported by the basic research foundation of CAIQ (2007JK010) and the research foundation of nonprofit industry of China (10-40). F. Zhang and X. Qi contributed equally to this work.

\section{References}

[1] T. Huppertz, P. F. Fox, K. G. de Kruif, and A. L. Kelly, "High pressure-induced changes in bovine milk proteins: a review," Biochimica et Biophysica Acta, vol. 1764, no. 3, pp. 593-598, 2006.

[2] H. Bouaouina, A. Desrumaux, C. Loisel, and J. Legrand, "Functional properties of whey proteins as affected by dynamic high-pressure treatment," International Dairy Journal, vol. 16, no. 4, pp. 275-284, 2006.

[3] A. S. Lopes, J. S. Garcia, R. R. Catharino, L. S. Santos, M. N. Eberlin, and M. A. Z. Arruda, "Cloud point extraction applied to casein proteins of cow milk and their identification by mass spectrometry," Analytica Chimica Acta, vol. 590, no. 2, pp. 166 $172,2007$.

[4] D. L. Kleinberg, J. Todd, and G. Babitsky, "Inhibition by estradiol of the lactogenic effect of prolactin in primate mammary tissue: reversal by antiestrogens LY 156758 and tamoxifen," Proceedings of the National Academy of Sciences of the United States of America, vol. 80, no. 13 I, pp. 4144-4148, 1982.

[5] K. R. Acharya, D. I. Stuart, N. P. C. Walker, M. Lewis, and D. C. Phillips, "Refined structure of baboon $\alpha$-lactalbumin at 1.7 $\AA$ resolution. Comparison with C-type lysozyme," Journal of Molecular Biology, vol. 208, no. 1, pp. 99-127, 1989.

[6] S. Aparecida Costa, A. Pessoa Jr., and I. Conceição Roberto, "Partitioning of xylanolitic complex from Penicillium janthinellum by an aqueous two-phase system," Journal of Chromatography B, vol. 743, no. 1-2, pp. 339-348, 2000.

[7] C. O. Rangel-Yagui, H. Lam, D. T. Kamei, D. I. C. Wang, A. Pessoa Jr., and D. Blankschtein, "Glucose-6-phosphate dehydrogenase partitioning in two-phase aqueous mixed (nonionic/cationic) micellar systems," Biotechnology and Bioengineering, vol. 82, no. 4, pp. 445-456, 2003.

[8] Z. F. Wang, M. Q. Zou, X. H. Qi, and Z. Y. Zhang, "Application of a nonionic surfactant Triton X-114 in the separation of proteins," Chemical Reagents, vol. 30, pp. 9-11, 2008 (Chinese). 


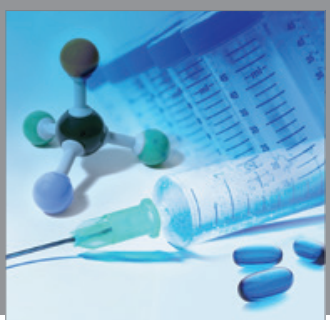

International Journal of

Medicinal Chemistry

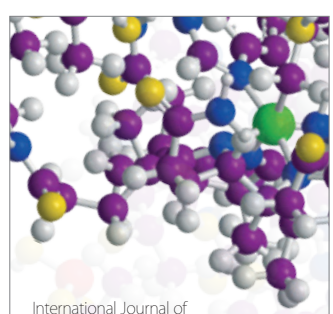

Carbohydrate Chemistry

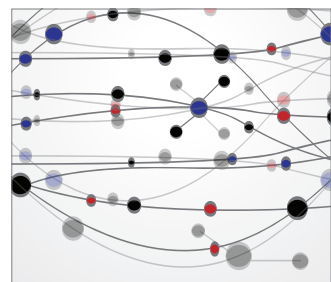

The Scientific World Journal
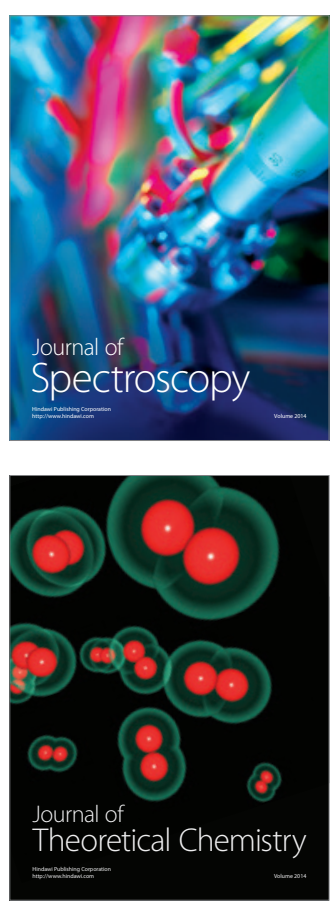
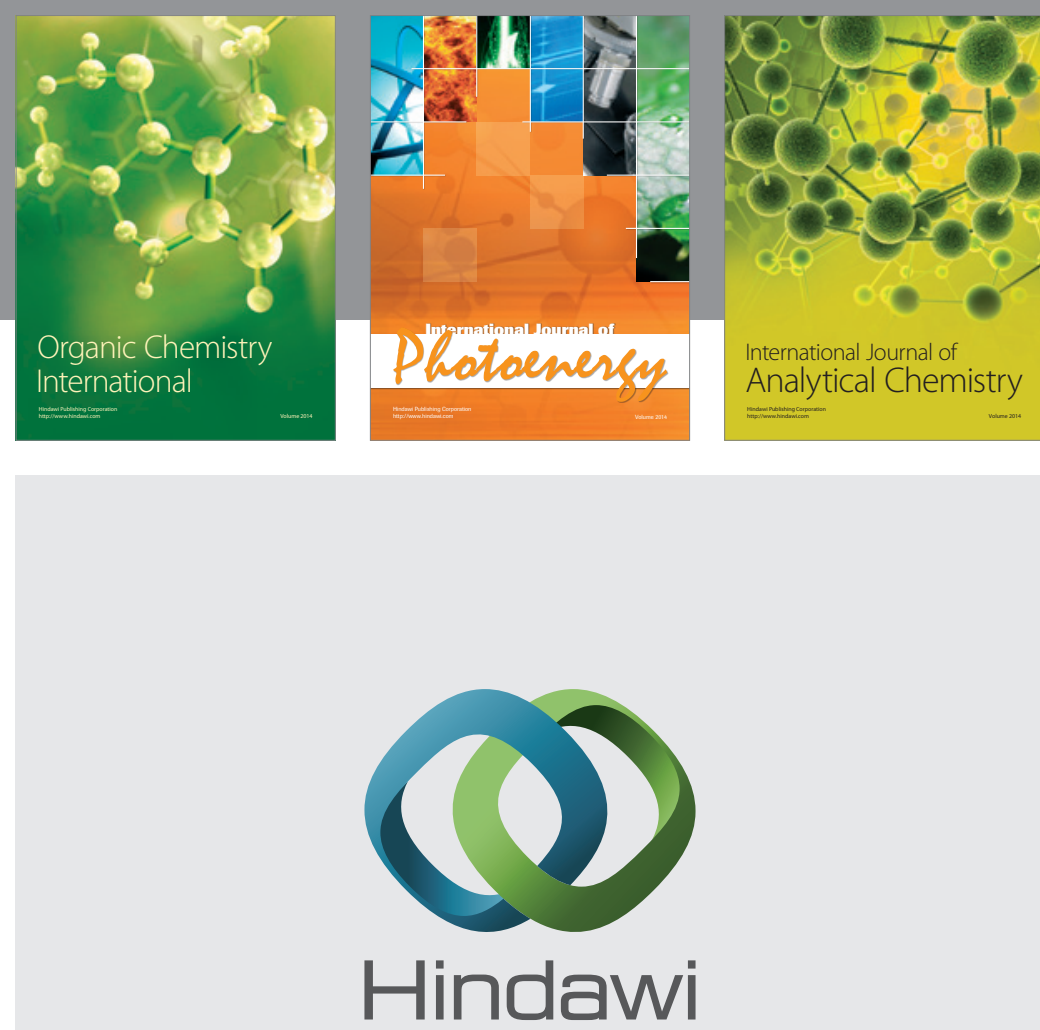

Submit your manuscripts at

http://www.hindawi.com
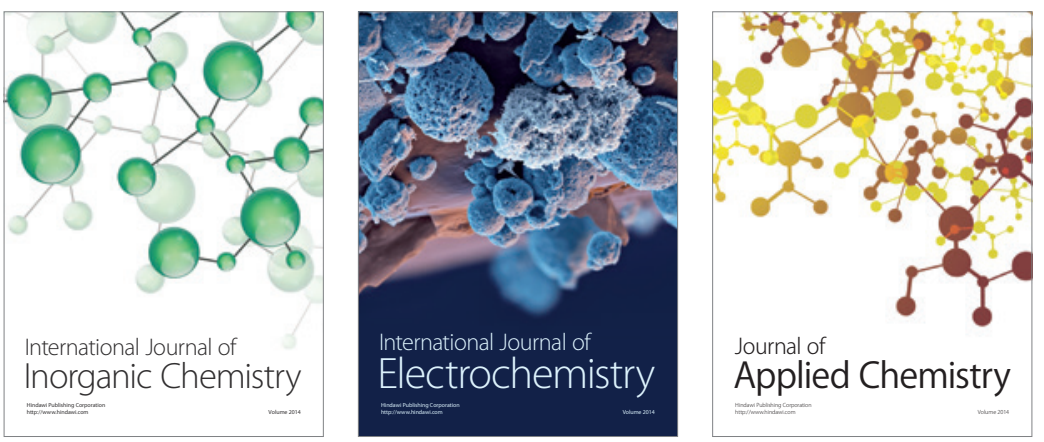

Journal of

Applied Chemistry
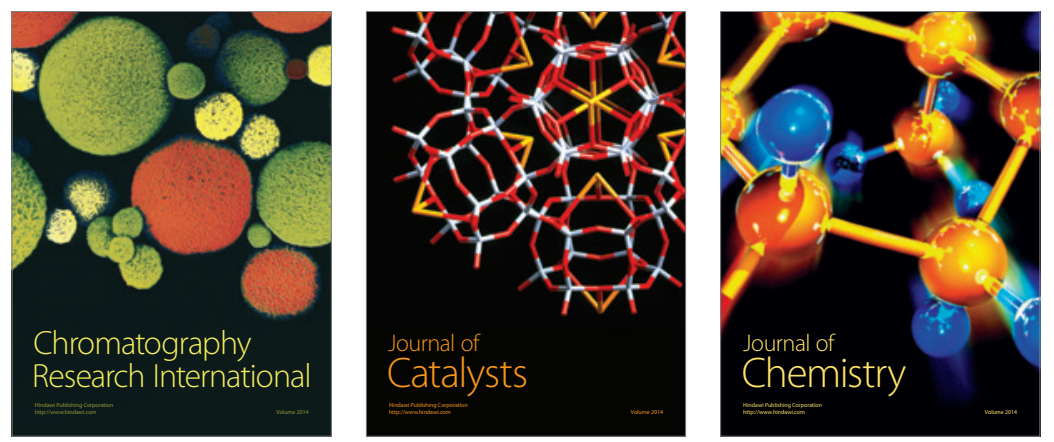
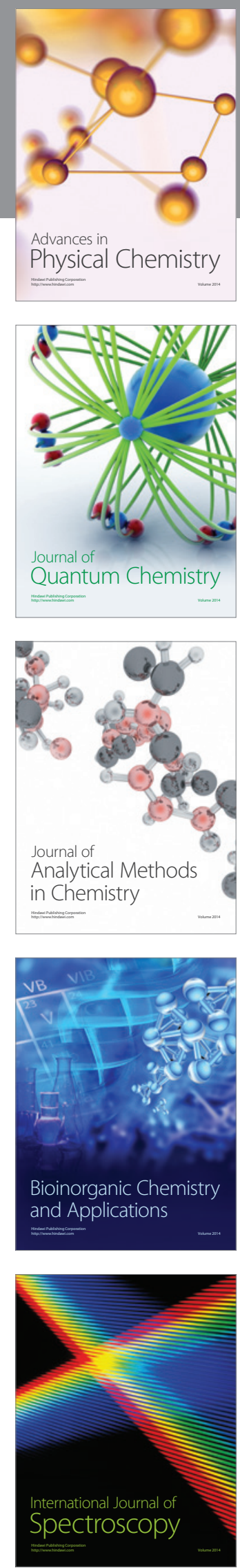